\title{
FRC: structural applications and standards
}

\author{
Marco di Prisco
}

Received: 11 July 2007 / Accepted: 11 June 2009/Published online: 11 August 2009

(C) RILEM 2009

Fibre Reinforced Concrete is becoming a new building material for structural design in national and international standards. The mechanical characteristics of this cement-based composite are very attractive to improve serviceability and even ultimate limit states, depending on the application, concrete mixture design, fibre type and content. With usual fibre contents, $<1.5 \%$ by volume, the material usually exhibit a softening behaviour in uniaxial tension. As a consequence, crack propagation is strongly affected by structural redundancy of the structure. In fact, the residual strength due to pull-out is not negligible and can be considered in the equilibrium conditions. This feature is very interesting for Fracture Mechanics people, because it takes advantage of the stability condition and uses a toughness approach where all the concepts developed in the last 20 years in the fracture mechanics of concrete framework become useful tools to design structures.

After the construction of suitable elements of famous examples (Fig. 1) like Post-Damer Platz foundations in Berlin, pre-cast tunnel segments introduced in well-known tunnel linings all over the world, plates or sheltering structures like sheet piles in The Netherland or retaining structures in Italy, thin walled

M. di Prisco $(\bowtie)$

Department of Structural Engineering, Politecnico

di Milano, Piazza Leonardo da Vinci 32,

20133 Milan, Italy

e-mail: marco.diprisco@polimi.it covering structures in Industrial and Commercial Buildings in Italy, light, cast in place, shell coverings like that of the Oceanographic Museum in Valencia, fibre reinforced concrete is representing a real alternative in the framework of Architecture and Civil Engineering.

The special issue is based on a selection of the material presented and discussed in the framework of the International Workshop on Fibre Reinforced Concrete held in Catania on June 22nd, 2007 in the occasion of Fracture Mechanics Concrete Structure 6th International Conference.

Because the main inhibitor for application of this technology in engineering practice, both in Europe and in North America, is the lack of appropriate codes and standards as well as suitable certification, the aim of the workshop was to bring together experts from all over the world, whose past and current research efforts have been responsible for advancing the state of the art of FRC and who are familiar with the associated professional practice issues, to discuss the key features of an International Standard like that in progress for the next FIB Model Code. ACI and RILEM have already undertaken major efforts to refine design methodologies. In fact, the most important step, still in progress, is the effort to propose the most reliable equations for structure design by using short discrete discontinuous fibres as diffuse reinforcement to improve both the cementitious composite performance at serviceability limit conditions, by increasing the small crack opening residual strength, and the ultimate 
Fig. 1 a Post-Damer Platz (by H. Falkner);

b Barcelona tunnel (by R. Gettu); c sheet piles in The Netherlands (by Walraven); d retaining structure in Italy (by M. di Prisco);

e Oceanographic museum in Valencia (by P. Sernà); f roof elements in Italy (by M. di Prisco); g ground slab tests (by G. Plizzari); h jointless rail track (by H. Falkner); i façade panels (by G. Plizzari); j thinshelled canopy in Canada (by CPV Group Architects \& Engineers Ltd)
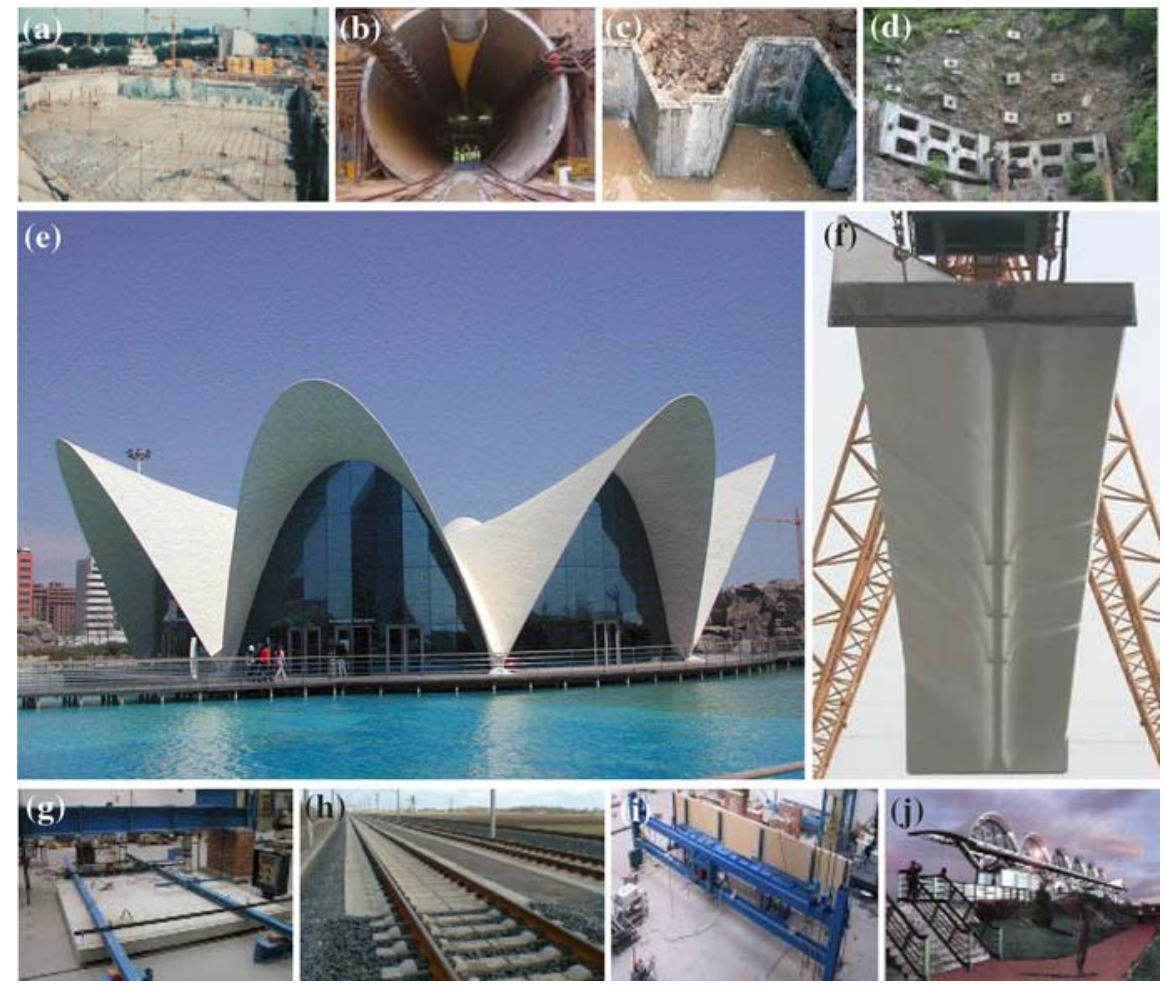

bearing capacity of structures for large crack openings, where fibres act as a partial replacement of conventional steel reinforcement. In special cases the use of high fibre contents can even completely replace conventional steel reinforcement showing a hardening controlled behaviour in bending: this feature is particularly interesting for thin elements, where traditional reinforcement cannot be easily used, because it requires minimum covers to guarantee durability.

The Special issue aims at giving the reader a general overview of possible structural applications of fibre reinforcement not only in Europe and USA with the contribution of Falkner, Walraven, Sernà and $\mathrm{Li}$, but also in Japan, Australia, China and India where the fibre market is growing in terms of quality and quantity respectively with the contribution of Rokugo, Foster, Luong and Appa Rao.

Two technical groups (TG8.3 and TG8.6) are working in the framework of FIB, respectively, on high performance materials characterized by a maximum compressive strength not exceeding $140 \mathrm{MPa}$ and Ultra High Performance Cementitious Composites (UHPFRCC) characterized by higher uniaxial compressive strength and large fibre contents: from the effort to recognise the common points of view highlighted by these two groups, a new chapter on Fibre Reinforced Concrete will be presented in the next Model Code to clarify the designer what is generally accepted by both the groups and what must be indicated in suitable documents prepared by each technical group. A paper on this topic (di Prisco, Plizzari and Vandewalle) is also presented to clarify the main concepts on which the two groups are discussing and their scientific bases.

It should also be emphasized that the knowledge on UHPFRCC materials is growing thanks to the contribution of RILEM TC HFC on wide range of different research topics, such as testing methods for hardening materials, ductility, cyclic behaviour, creep, strain rate sensitivity and multiaxial behaviour. A comprehensive review of the work done on these subjects can be found in the proceedings of the BEFIB VI conference organized in Varenna (Italy) in 2004 (see RILEM Proceedings 39), in the proceedings of the workshop held in Mainz (Germany) in 2007 (see RILEM Proceedings 53 edited by Reinhardt and Naaman) and finally in the last BEFIB VII Conference organized by Ravindra Gettu in the Indian Institute of Technology in Madras-Chennai South India. 
The special issue here presented also contains two contributions inspired by the open discussion that took place at the end of the workshop: the former concerns the strain rate sensitivity of steel fibre reinforced concrete and the latter presents an experimental investigation on sprayed tunnel linings that shows how the recent technology has to take into account several reinforcement solutions that can be profitably used according to different casting procedures.

Guest Editor Marco di Prisco

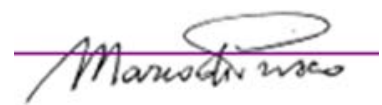

